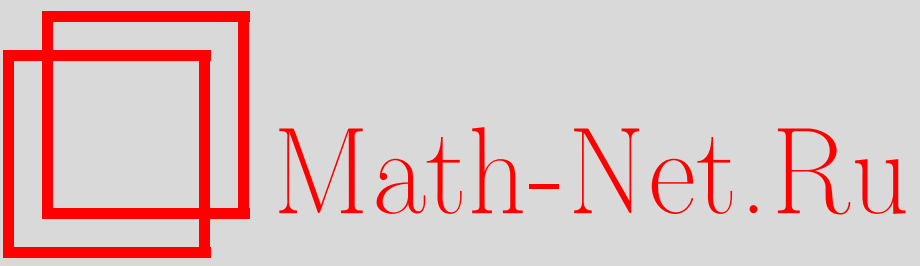

В. П. Радченко, А. В. Нехожин, А. Л. Матвеев, Математическое моделирование напряжённого состояния армированной костной ткани шейки бедра при статических нагрузках, Вестн. Сам. гос. техн. ун-та. Сер. Физ.мат. науки, 2011, выпуск 4(), 75-81

DOI: https://doi.org/10.14498/vsgtu1037

Использование Общероссийского математического портала Math-Net.Ru подразумевает, что вы прочитали и согласны с пользовательским соглашением http: //www. mathnet.ru/rus/agreement

Параметры загрузки:

IP : 34.229 .108 .108

26 апреля 2023 г., $07: 51: 20$ 


\title{
Биомеханика
}

\author{
УДК 616.71-001.5:539.4.014.1
}

\section{МАТЕМАТИЧЕСКОЕ МОДЕЛИРОВАНИЕ НАПРЯЖЁННОГО СОСТОЯНИЯ АРМИРОВАННОЙ КОСТНОЙ ТКАНИ ШЕЙКИ БЕДРА ПРИ СТАТИЧЕСКИХ НАГРУЗКАХ}

\author{
В. П. Радченко ${ }^{1}$ А.В. Нехожин ${ }^{1}$ А. Л. Матвеев ${ }^{2}$ \\ 1 Самарский государственный технический университет, \\ 443100, Самара, ул. Молодогвардейская, 244. \\ 2 Центральная городская больница, \\ 446200, Самарская обл., Новокуйбышевск, ул. Пирогова, 1. \\ E-mails: radch@samgtu.ru, stswoon@yandex.ru, mal57@rambler.ru
}

\begin{abstract}
Выполнены исследования влияния армирования на напряљённо-деформированное состояние костной ткани шейки бедра при статических нагрузках. Показано, что армирующие элементы приводят к снижению интенсивности напряженного состояния костной ткани в наиболее нагруженных областях. Даны рекомендачии по прочедуре армирования, по выбору типа армирующего элемента и его геометрии. Результаты выполненных исследований могут служить обоснованием методов профилактики переломов шейки бедра за счёт предварительного армирования в медицинской практике.
\end{abstract}

Ключевые слова: бедренная кость, имплантат, армирование, геометрическое моделирование, метод конечных элементов, напряжённо-деформированное состояние.

Введение. Актуальность проблемы переломов шейки бедренной кости у лиц пожилого и старческого возраста [1], а также недостатки применяемых в настоящее время методов и средств предупреждения переломов [1-5] вынуждают искать и разрабатывать новые пути и методики активной профилактики переломов. А. Л. Матвеев предложил хирургическую методику профилактики переломов шейки бедренной кости [6] путём армирования её имплантатами с целью увеличения прочности системы «костная ткань - имплантат». После проведения нескольких экспериментальных операций профилактического армирования с применением канюлированных и губчатых винтов автор [6] пришёл к выводу, что известные и применяемые для остеосинтеза сломанной шейки бедренной кости имплантаты не вполне отвечают требованиям повышения надежности биомеханической конструкции. В связи с этим были предложены новые оригинальные конструкции имплантатов, на которые получены патенты РФ [7-9]. Однако их внедрение в клиническую практику требует предварительного экспериментального и теоретического исследования влияния имплантатов на прочность биомеханической конструкции

Владимир Павлович Радченко (д.ф.-м.н., проф.), зав. кафедрой, каф. прикладной математики и информатики. Анатолий Вадимович Нехожин, аспирант, кафедра прикладной математики и информатики. Анатолий Лъвович Матвеев (к. медиц. н.), врач-ординатор, травматологическое отделение. 

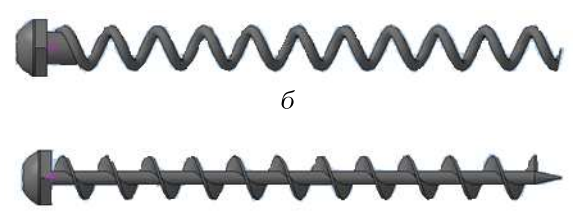

$B$

Рис. 1. Типы имплантатов: а) бификсирующая спица; б) винт-штопор; в) шнековый винт

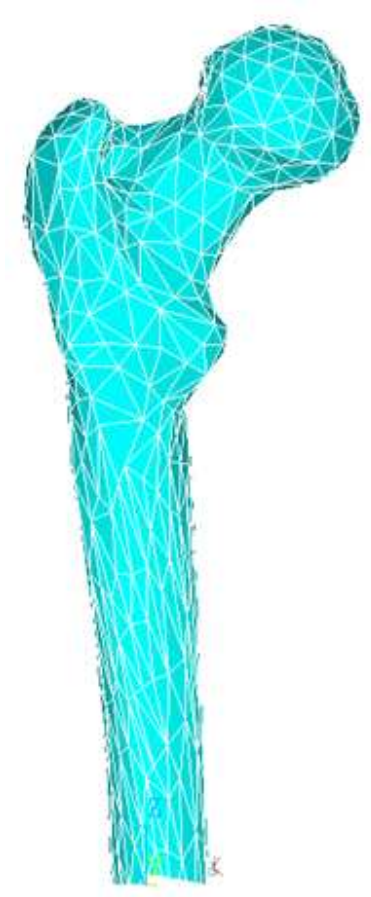

Рис. 2. Конечно-элементная модель бедренной кости «костная ткань - имплантат» при внешних нагрузках, моделирующих реальную ситуацию, приводящую к переломам в области шейки бедренной кости. Первые попытки экспериментального исследования влияния армирования на прочность костной ткани шейки бедра выполнены в работе [10], а попытки математического моделирования напряжённо-деформированного состояния для частных видов нагрузки и геометрического положения имплантата выполнены в [11]. Целью настоящей работы является детальное исследование влияния типа имплантата и его геометрического расположения на напряжённо-деформированное состояние биокомпозитного материала в шейке бедра.

1. Типы имплантатов, геометрическое моделирование и построение конечно-элементной модели. В настоящей работе рассматривались имплантаты трёх видов, представленные на рис. 1.

Бификсирующая спица (рис. 1,a) представляет собой цилиндрическое тело диаметром 2,5 мм с резьбой на конце и в центральной её части, предусмотренной для фиксации в головке бедренной кости и наружном кортикальном слое области большого вертела.

Винт-штопор (рис. 1, б) представляет собой спирально закрученную спицу сечением 2,5 мм с резьбой (наружный диаметр витка - 8,0 мм, шаг витка - 8,0 мм) и головкой, снабжённой шлицем под отвёртку.

Шнековый винт (рис. 1, в) представляет собой спицу со спирально закрученной пластиной, у которой имеется головка, снабжённая шлицем под отвёртку.

Построение геометрии кости является первым этапом решения задачи о напряжённо-деформированном состоянии методом конечных элементов.

Для создания конечно-элементной модели бедренной кости использован макет бедра, применяемый в медицинских учреждениях для проведения опытов на прочность. Геометрическая модель была уточнена при помощи 3Dмодели кости, полученной путём лазерного сканирования, взятой с сайта Titanium Bone Project (webspace.utexas.edu/reyesr/titanium/3D_models.html). Для построения объёмной модели в конечно-элементном пакете ANSYS [12] разработана программа, генерирующая последовательность ANSYS-команд. На рис. 2 представлена конечно-элементная модель бедренной кости. 
Так как вставка имплантатов может производиться под разными углами и в разных местах, для автоматизации «внедрения» имплантатов в конечно-элементную модель кости разработана программа, входными данными которой являются тип имплантата и смещение локальной системы координат имплантата относительно глобальной системы координат кости, а выходными данными - набор ANSYS-команд, в результате выполнения которых строится конечно-элементная модель кости с выбранным имплантатом. Типичные расположения имлантатов в кости приведены на рис. 3 .

2. Краевые условия и механические характеристики костной ткани. Для описания механических характеристик костной ткани использовалась диаграмма мгновенного деформирования компактной костной ткани человека возрастной группы 6080 лет, представленная на рис. 4 [13]. Это связано с тем, что возрастная группа людей 60-80 лет относится к группе риска по остеопорозу и другим хроническим заболеваниям и чаще всего подвержена переломам шейки бедра.

На рис. 5 схематически представлены внешние нагрузки и закрепления кости, соответствующие падению человека с высоты своего роста. Равнодействующая распределённых сил принималась равной $8000 \mathrm{H}$, что согласуется с данными работы [14]. Краевая задача решалась в упругопластической постановке.

3. Улучшение конечно-элементного разбиения. Поскольку структурные элементы (частицы) костной ткани имеют размеры 5-50 мкм, то требуется достаточно объёмное конечно-элементное разбиение соответствующей области, что может привести даже к ограничениям вы-

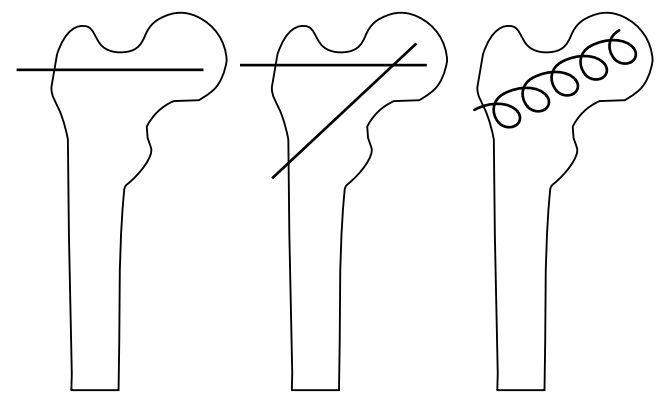

Рис. 3. Типичные расположения имплантатов в кости

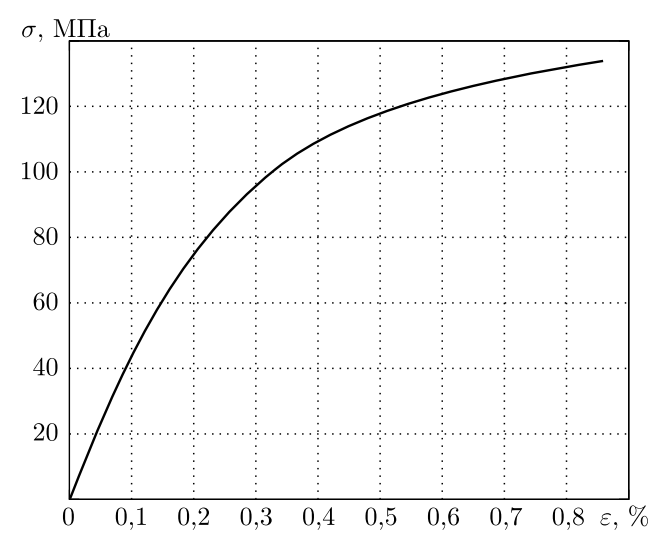

Рис. 4. Диаграмма мгновенного деформирования компактной костной ткани человека из возрастной группы 60-80 лет [13]

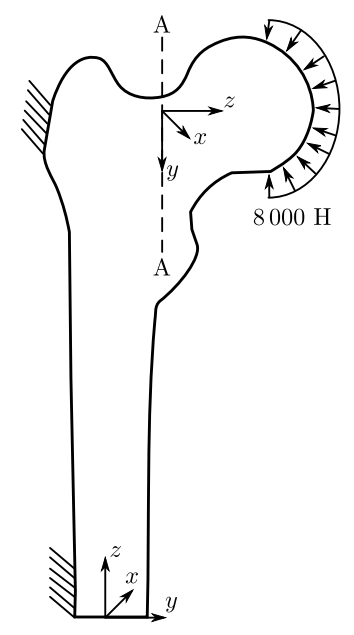

Рис. 5. Нагрузки и закрепления кости при падении человека 
числительных ресурсов персонального компьютера. Поэтому для реализации вычислительной схемы в пакете ANSYS поставленная задача решалась в два этапа. Сначала строилась «грубая» конечно-элементная сетка, решалась задача и определялись наиболее нагруженные области; далее в этих областях производилось уточнение конечно-элементной сетки около конкретных точек. Для этой цели разработана программа, которая на основании следующих данных:

- количество узлов около точки, в которых происходит уточнение сетки;

- степень уточнения сетки;

- список точек, около которых производится уточнение сетки;

- набор узлов конечно-элементной сетки, которую нужно уточнить генерирует набор ANSYS-команд для уточнения конечно-элементной сетки.

4. Результаты расчёта напряжённого состояния в шейке бедренной кости. В результате предварительных исследований было показано, что получаемое численное решение устойчиво: измельчение конечно-элементной сетки прекращалось тогда, когда интенсивность напряжений напряжений в наиболее нагруженных точках переставала изменяться.

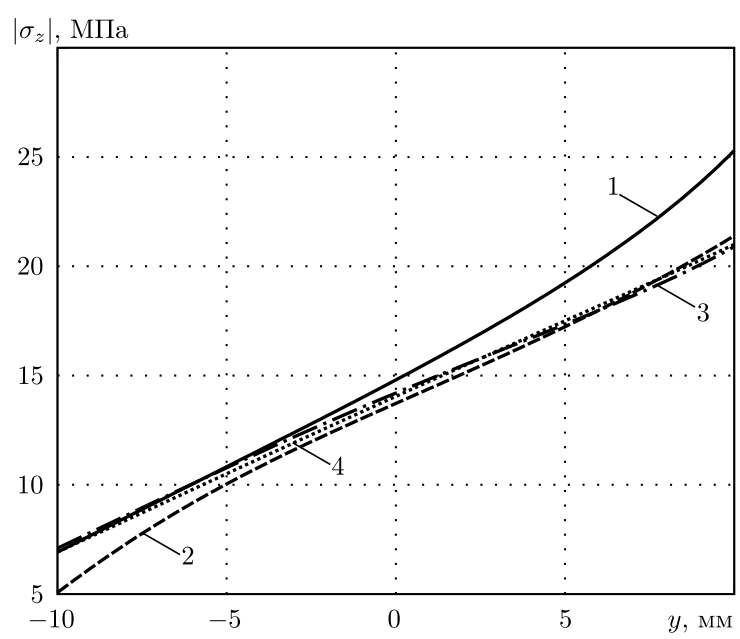

Рис. 6. Распределение $\sigma_{z}=\sigma_{z}(y)$ в сечении $\mathrm{A}-\mathrm{A}$ шейки бедренной кости: 1) интактная кость; 2) бификсирующая спица; 3) две бификсирующие спицы; 4) винт-штопор

Анализ компонент тензора напряжений в сечении $\mathrm{A}-\mathrm{A}$ шейки бедренной кости (см. рис. 5) показал, что наибольшим (по модулю) значением обладает нормальная компонента напряжения $\sigma_{z}$ (по отношению к сечению A-A) в локальной системе координат. Установлено, что напряжения в интактной кости (без имплантатов) и в армированной биокомпозитной кости имеют большие величины по краям сечения, что частично связано с наличием эффекта изгиба. Кроме этого, внутри сечения наблюдаются скачки напряжений на границе перехода от костной ткани к металлическому имплантату, свидетельствующие о том, что происходит «перекачка» напряжений от костной ткани к имплантату, т. е. имплантат берёт на себя часть напряжений, разгружая тем самым костную ткань. В качестве примера на рис. 6 приведено распределение напряжений $\sigma_{z}$ по внутренней части сечения $\mathrm{A}-\mathrm{A}$ вдоль координаты $y$ локальной системы координат, из которого наглядно видно, что максимальное (по мо-

\begin{tabular}{l|c|c|c|c|c|c|c}
\hline Имплантат & $\left|\sigma_{x}\right|$, МПа & $\left|\sigma_{y}\right|$, МПа & $\left|\sigma_{z}\right|$, МПа & $\left|\sigma_{x y}\right|$, МПа & $\left|\sigma_{y z}\right|$, МПа & $\left|\sigma_{z x}\right|$, МПа & $\delta \sigma, \%$ \\
\hline- & 116 & 194 & 203 & 39 & 66 & 25 & - \\
Спица & 88 & 138 & 184 & 16 & 75 & 21 & 10,3 \\
Две спицы & 97 & 171 & 185 & 31 & 66 & 18 & 9,7 \\
Штопор & 116 & 191 & 196 & 37 & 71 & 25 & 3,6 \\
\hline
\end{tabular}


дулю) напряжение $\sigma_{z}$ с имплантатами ниже, чем в интактной кости.

В таблице приведены значения компонент тензора напряжения в максимально нагруженной точке костной ткани с имплантатами и без них, а также $\delta \sigma$ - величина снижения напряжения. Полученные результаты показывают, что в целом имплантаты снижают напряжённое состояние в опасном сечении шейки бедренной кости, а имплантаты в виде одной или двух спиц являются наиболее эффективными из рассмотренных.

Выводы. Анализ решений соответствующих краевых задач для оценки напряжённого состояния интактной (без армирования) костной ткани шейки бедра и с учётом армирования позволяет сделать следующие выводы:

- напряжения (по модулю) внутри кости существенно ниже, чем на её поверхности;

- в целом при применении имплантатов в кости наибольшие (по модулю) напряжения в кости снижаются, что свидетельствует о целесообразности предварительного армирования материала костной ткани шейки бедренной кости у пожилых лиц, входящих в группу риска, поскольку эта процедура позволяет снизить вероятность перелома вследствие снижения критических напряжений в опасных областях за счёт «перекачки» части нагрузки в элемент армирования.

Таким образом, проведённое исследование может с позиции механики деформируемого твердого тела служить определённым обоснованием метода превентивной профилактики переломов шейки бедра за счёт предварительного армирования.

\section{БИБЛИОГРАФИЧЕСКИЙ СПИСОК}

1. Пирожкова Т. А. Медико-социальная экспертиза и реабилитация инвалидов с последствиями переломов шейки бедренной кости: Автореф. дисс. ... канд. мед. наук. М., 1998. 34 c. [Pirozhkova T. A. Medical and social expertise and rehabilitation of handicapped persons with the consequences of femoral neck fractures: PhD. Thesis (Medical). Moscow. 34 pp.]

2. Родионова С.С., Колондаев А.Ф., Солод Э.И. Комбинированное лечение переломов шейки бедренной кости на фоне остеопороза // Русский медицинский журнал, 2004. T. 12, № 24. C. 1388-1392. [Rodionova S. S., Kolondaev A. F., Solod É I. Combined treatment of femoral neck fractures in osteoporosis // Russkiy Medicinskiy Zhurnal, 2004. Vol.12, no. 24. Pp. 1388-1392].

3. Кемпф И., Таглан Ж. Гамма-гвоздь: исторический обзор // Остеосинтез, 2007. Т. 1, № 1. C. 12-17. [Kempf I., Taglan G. Gamma nail. A historical overview // Osteosintez, 2007. Vol. 1, no. 1. Pp. 12-17].

4. Osteoporosis: Etiology, Diagnosis, and Management/ eds. B. Lawrence Riggs, L. Joseph Melton III. New York: Raven Press, 1988. 501 pp.; русск. пер.: Остеопороз. Этиология, диагностика, лечение / ред. Б. Лоренс Риггз., Л. Джозеф Мелтон III. СПб.: Бином, Невский диалект, 2000. 560 с.

5. Шен В.И. Осложнения при использовании стандартного и длинного гамма-гвоздей и способы их предотвращения // Остеосинтез, 2007. Т. 1, №1. С. 17-25. [Shen W. Y. Complications in the use of standard and long gamma nail and methods of their prevent // Osteosintez, 2007. Vol.1, no. 1. Pp. 17-25].

6. Матвеев А. Л. Оперативный способ профилактики переломов шейки бедренной кости: Патент РФ на на изобретение № 2316280 от 10.02.2008. [Matveev A. L. Operative way of femoral neck fractures preventing: Invention patents of the Russian Federation. No. 2316280 of February 10, 2008]. 
7. Матвеев А. Л. Устройство для армирования шейки бедренной кости и превентивной профилактики её переломов: Патент РФ на полезную модель № 101351 от 20.01.2011. [Matveev A.L. Device for reinforcement of the femoral neck and proactive prevention of their fracture: Utility model patents of the Russian Federation. No. 101351 of January 20, 2011].

8. Матвеев А. Л. Устройство для армирования биологического композитного материала и превентивной профилактики шейки бедренной кости: Патент РФ на полезную модель № 91845 от 10.03.2010. [Matveev A.L. Device for reinforcement of biological composite materials and proactive prevention for femoral neck: Utility model patents of the Russian Federation. No. 91845 of March 10, 2010].

9. Матвеев А.Л., Нехожин А. В. Устройство для армирования шейки бедренной кости и превентивной профилактики переломов: Патент РФ на полезную модель № 98901 от 10.11.2010. [Matveev A.L., Nekhozhin A. V. Device for reinforcement of the femoral neck and proactive prevention of fracture: Utility model patents of the Ruoral neck assian Federation. No. 98901 of November 10, 2010].

10. Минасов Б. Ш., Ханин М. Ю., Якупов Р. Р., Минасов Т. Б. Результаты стендовых испытаний системы кость - имплантат - кость в условиях стандартного остеосинтеза при переломах проксимального отдела бедра // Казанский медичинский журнал, 2010. T. 91, №1. C. 40-44. [Minasov B. Sh., Khanin M. Yu., Yakupov P.P., Minasov T. B. The results of bone - implant - bone bench tests of standard osteosynthesis during fractures of the proximal part of the thigh bone// Kazanskiy Medicinskiy Zhurnal, 2010. Vol. 91, no.1. Pp. 40-44].

11. Нехожин А.В., Радченко В.П., Матвеев А.Л. Математическое моделирование напряженного состояния в шейке бедра в момент удара при падении человека/ В сб.: Труды восъмой Всероссийской научной конферениии с международным участием. Часть 1: Математические модели механики, прочности и надёжности элементов конструкций / Матем. моделирование и краев. задачи. Самара: СамГТУ, 2011. С. 132-135. [Nekhozhin A. V. Radchenko V. P., Matveev A. L. Mathematical modeling of femoral neck stress state at the moment of impact in the fall of man/ In: Proceedings of the Eighth All-Russian Scientific Conference with international participation. Part 1/ Matem. Mod. Kraev. Zadachi. Samara: SamGTU, 2011. Pp. 132-135].

12. Басов К.А. ANSYS. Справочник пользователя. М.: ДМК Пресс, 2005. 640 с. [Basov K. A. ANSYS. User's manual. Moscow: DMK Press, 2005. 640 pp.]

13. Вини, $X$. Изменение механических свойств компактной костной ткани человека в зависимости от возраста // Механика полимеров, 1975. № 4. С. 659-663; англ. пер.: Vinz H. Change in the mechanical properties of human compact bone tissue upon aging // Mechanics of Composite Materials, 1975. Vol. 11, no. 4. Pp. 568-571.

14. Myers E. R., Wilson S. E. Biomechanics of Osteoporosis and Vertebral Fracture// Spine, 1997. Vol. 22, no. 24S. Pp. 25S-31S.

Поступила в редакцию 20/VIII/2010;

в окончательном варианте - 20/IX/2010. 
MSC: 97M60; 74L15, 74S05

\section{MATHEMATICAL MODELING OF THE STRESS STATE \\ OF REINFORCED BONE TISSUE OF THE FEMORAL NECK WITH STATIC LOAD}

\section{V.P. Radchenko, A. V. Nekhozhin, A.L. Matveev}

1 Samara State Technical University,

244, Molodogvardeyskaya st., Samara, 443100, Russia.

2 Central City Hospital,

1, Pirogov str., Novokuybyshevsk, Samara Region, Russia, 446200.

E-mails: radch@samgtu.ru, stswoon@yandex.ru, mal57@rambler.ru

The research of the influence of bone reinforcement on the stress-strain state of bone tissue in the femoral neck is completed. It is shown, that the reinforcement decreases the intensity of the stress-strain state of bone tissue in the most dangerous areas. Recommendations about the procedure of reinforcement, location and geometry of implants are formulated according to these calculations. Results of the current research can justify the methods for preventing hip fractures due to the prior reinforcement in medical practice.

Key words: femur, implant, reinforcement, geometric modeling, finite element method, stress-strain state.

Original article submitted 20/VIII/2010; revision submitted 20/IX/2010.

Vladimir P. Radchhenko (Dr. Sci. (Phys. \& Math.)), , Head of Dept., Dept. of Applied Mathematics \& Computer Science. Anatoliy V. Nekhozhin, Postgraduate Student, Dept. of Applied Mathematics \& Computer Science. Anatoliy L. Matveev (Ph. D. (Medical)), PhysicianOrdinator, Casualty Department. 